\title{
HPLC Method for Ethylenethiourea in Biological and Environmental Samples
}

\author{
Ailyn G. Manglicmot-Yabes, ${ }^{1,2}$ Edna L. Liwag, ${ }^{1}$ Lynn Crisanta R. Panganiban, ${ }^{1,2}$ and Nelia P. Cortes-Maramba ${ }^{1,2}$ \\ ${ }^{1}$ Department of Pharmacology and Toxicology, College of Medicine, University of the Philippines Manila \\ ${ }^{2}$ National Poison Management and Control Center, Philippine General Hospital, University of the Philippines Manila
}

\begin{abstract}
Objective. In view of both the economic importance of ethylenebisdithiocarbamate (EBDC) fungicides in the current agricultural practice and the potential health hazards associated with ethylenethiourea (ETU) exposure, this study aimed to develop and validate a high-pressure liquid chromatography (HPLC) method to determine ETU in biological and environmental samples.
\end{abstract}

Methods. The samples were pre-treated according to sample types and were analyzed for ETU using a reversedphase HPLC system (JASCO ${ }^{\mathrm{R}}$ ) equipped with UV detector set at $230 \mathrm{~nm}$ using C18 bonded silica column and a mobile phase of $0.05 \mathrm{M}$ ammonium acetate in methanol (95:5).

Results. The method showed a limit of detection of $0.2 \mathrm{ug} / \mathrm{L}$, with a precision of 3.33 to $12.86 \% \mathrm{CV}$ and accuracy of $>90 \%$ at 1,10 and $100 \mathrm{ug} / \mathrm{L}$ of ETU in all sample types. The calibration curve was linear from 1 to $200 \mathrm{ug} / \mathrm{L}$ for blood, air and water samples and 1 to 2000 ug/L for urine.

Conclusion. This method showed an acceptable accuracy, precision, sensitivity and specificity and was used subsequently to determine ETU levels in blood, urine, air, soil and water samples among banana plantation workers.

Key Words: Ethylenethiourea, Ethylenebisdithiocarbamate, Mancozeb

Corresponding author: Ailyn G. Manglicmot-Yabes, RMT, MScPH Department of Pharmacology and Toxicology College of Medicine

University of the Philippines Manila

547 Pedro Gil St., PO Box 593, Manila 1000 Philippines

Telephone: +639473745190

Email: ailynyabes@gmail.com

\section{INTRODUCTION}

Ethylenethiourea (ETU) is both a degradation and by-product of ethylenebisdithiocarbamate (EBDC) formulations produced in the presence of moisture and oxygen during manufacture and even during storage. It is thought to be the source of most of the toxicity associated with EBDC and exposures occur mainly by inhalation and by absorption under occupational conditions. ${ }^{1-5}$ EBDC, one of the subclasses of dithiocarbamates, is among the most commonly employed organic fungicides in the current agricultural practice. It is registered for use in almost 120 countries throughout the world and it is usually used as fungicide in banana plantations. ${ }^{6}$ In order to assess the potential health hazards associated with EBDC, there is a need to develop a method for determination of ETU in biological and environmental samples, as indicator of EBDC exposure.

ETU has a chemical formula of 2-imidazolidinethione; empirical formula $\mathrm{C}_{3} \mathrm{H}_{6} \mathrm{~N}_{2} \mathrm{~S}$; and a molecular weight of $102.16 \mathrm{~g} / \mathrm{mol}$. It is soluble in water and sparingly soluble in ethyl acetate and low boiling alcohols such as methanol, ethanol and isopropyl alcohol. The analytical methods for ETU described in early studies utilized gas chromatography 
(GC) and high pressure liquid chromatography (HPLC). ${ }^{7-10}$ The more recent studies on ETU, used either gas chromatography mass spectrometry-mass spectrometry (GCMS/MS) or liquid chromatography mass spectrometrymass spectrometry (LCMS/MS) with solid phase extraction (SPE) and other advance techniques of sample extraction, concentration and purification. ${ }^{11-17}$ However, most of the GC methods need the derivatization of ETU, rendering the procedure more complicated and the probability of ETU loss during the sample preparation step. Likewise, the HPLC methods reported in the literatures required different detectors and sample preparation techniques that vary depending on the sample type. Thus, limit its ease of use in environmental and health assessment studies, where various biological and environmental samples are submitted for analysis. Furthermore, though various chromatographic methods to determine ETU in biological fluids and food crops have been described in the literature, none of these can be easily adapted to laboratories with limited resources for technologies such as mass spectrometry and advanced sample preparation techniques.

In view of both the economic importance of EBDC fungicides in current agricultural practice and the potential health hazards associated with ETU exposure, this study aimed to develop and validate a method which is accurate and simple but with efficient extraction procedure applicable to sample types commonly submitted for analysis of ETU, as an indicator of EBDC exposure.

\section{MATERIALS AND METHODS}

\section{Ethical Statement}

Collection of biological samples used during the method development and validation phase were undertaken with understanding and written consent of each human subject. This was concurrent with the ethics review done on the health assessment study among banana plantation workers in the Philippines.

\section{Apparatus}

A reversed-phase HPLC system (JASCO ${ }^{R}$ Pump Model $980 \mathrm{~S}$ ) equipped with ultraviolet (UV) detector $\left(\mathrm{JASCO}^{\mathrm{R}}\right.$ UV-VIS Model 97) set at $230 \mathrm{~nm}$ and a $\mathrm{C}_{18}$ bonded silica column with $0.05 \mathrm{M}$ ammonium acetate in methanol (95:5) as mobile phase was used. The sample injection volume was $50 \mathrm{uL}$ with an injection flow of $1.0 \mathrm{ml} /$ minute.

\section{Reagents, Calibration standards and quality control samples}

All solvents used were HPLC grade from Burdick and Johnson Laboratories, Morristown, New Jersey, USA and the ETU (2-Imidazolidinethione) standard was obtained from Sigma-Aldrich Pte. Ltd. Singapore. The stock solution of ETU (5,000 ug/L) was prepared by diluting the ETU standard with methanol. These solutions were refrigerated at $2-8^{\circ} \mathrm{C}$ until use. All chemicals were handled following the recommended safety precautions.

Calibration standards were prepared in ETU-free serum at concentrations ranging from 1 to $200 \mathrm{ug} / \mathrm{L}$ and in ETUfree pooled urine at concentrations ranging from 1 to 2000 ug/L. For environmental samples, calibration standards were prepared in ETU-free water at concentrations ranging from 1 to $200 \mathrm{ug} / \mathrm{L}$. Quality control (QC) samples were prepared by spiking ETU-free serum, ETU-free urine and ETU-free water sample with the ETU standards to obtain the final concentrations of 1,10 and $100 \mathrm{ug} / \mathrm{L}$.

\section{Sample Extraction Procedure}

The different sample types, matrix-specific calibrators and quality controls were pre-treated prior to extraction with ethyl acetate.

Briefly, serum or urine $(0.5 \mathrm{ml})$ was initially diluted with distilled water (1:1) and $2 \mathrm{ml}$ of ethyl acetate was added to serum or urine sample. The mixture was vortexed for 5 minutes and centrifuged at $2000 \mathrm{rpm}$ for 10 minutes. After centrifugation, $1.0 \mathrm{ml}$ of extract was collected.

For the air sample, the air filter was immersed in $10 \mathrm{ml}$ water and kept in water bath at $60^{\circ} \mathrm{C}$ for 45 minutes to allow the liberation of ETU adsorbed in the filter, the air filter was removed afterwards and the sample was extracted with 20 $\mathrm{ml}$ ethyl acetate using a mechanical shaker for twenty (20) minutes and centrifuged at $2000 \mathrm{rpm}$ for 10 minutes. After centrifugation, $10 \mathrm{ml}$ of the extract was collected.

For soil sample, it was first air dried at room temperature $\left(22^{\circ} \mathrm{C}\right)$ to reduce the moisture content. After drying, 1 gram of soil was dissolved in $10 \mathrm{ml}$ distilled water and vortexed for 5 minutes. The mixture was filtered using Whatman No. 1 filter paper and the filtrate was placed in a separatory funnel and extracted with $10 \mathrm{ml}$ of ethyl acetate using a mechanical shaker for twenty (20) minutes and centrifuged at $2000 \mathrm{rpm}$ for 10 minutes. After centrifugation, $5 \mathrm{ml}$ of the extract was collected.

For water sample, $50 \mathrm{ml}$ was placed in a separatory funnel and extracted with $20 \mathrm{ml}$ ethyl acetate using a mechanical shaker for twenty (20) minutes and centrifuged at $2000 \mathrm{rpm}$ for 10 minutes. After centrifugation, $10 \mathrm{ml}$ of the extract was collected.

The extract from all sample types was evaporated to dryness at $37^{\circ} \mathrm{C}$ and the residue was reconstituted with $1 \mathrm{ml}$ of mobile phase and used for HPLC analysis.

\section{Method Validation}

After the sample preparation and the HPLC operating parameters were optimized, the method was validated for each sample type, following the standard method validation protocols for the following parameters; specificity/selectivity, calibration curve/linearity, limit of detection (LOD), limit of quantification (LOQ), accuracy (bias), precision and percentage recovery. To determine the specificity, ten blank samples using the different matrix were run and observed 
for interfering signals. The calibration curve was built using five to seven varying concentrations, each level was run in five replicates and the means of the five replicates per level were plotted. The linearity of the method was evaluated by calculation of the regression line by the method of least squares and expressed by the correlation coefficient $\left(\mathrm{r}^{2}\right)$. Limit of detection was determined based on the standard deviation of the blank sample response, wherein $\mathrm{S} / \mathrm{N} \geq 3$. Limit of quantitation was the lowest level of the calibration curve that meets the accuracy $(>80 \%)$ and precision $(<15 \% \mathrm{CV})$ criteria. To determine the accuracy and precision, QC samples were prepared in house by spiking ETU-free serum, ETU-free urine and ETU-free water sample with the ETU standards to obtain the final concentrations of 1,10 and $100 \mathrm{ug} / \mathrm{L}$. QC samples were assayed in five replicates per level and run in four different days. Accuracy by recovery was expressed as the percent deviation between the nominal and the mean of the measured concentrations in each of the concentration. Precision was expressed as \% coefficient of variation (\%CV) of the quality control samples. The concentration of ETU in the samples was calculated based on the calibration curve prepared for each type of sample on each analytical run. Dilution factors were considered and the results were expressed as ug/L. ETU standards and in-house matrixspecific QC samples were injected in every analytical run.

\section{RESULTS AND DISCUSSION}

The method described in this study showed an acceptable accuracy, precision, sensitivity and specificity for the determination of ETU in blood, urine, water, soil and air. This reversed-phase HPLC system $\left(\mathrm{JASCO}^{\mathrm{R}}\right)$ was equipped with a UV detector, with $\mathrm{C}_{18}$ bonded silica column and mobile phase of $0.05 \mathrm{M}$ ammonium acetate in methanol (95:5). It is similar to what was reported by Kobayashi which uses the same detector and column. ${ }^{18}$ Under this chromatographic condition, with a sample injection volume of $50 \mathrm{uL}$ and injection flow of $1.0 \mathrm{ml} / \mathrm{min}$, the ETU gave a retention time of $6.67(6.53-6.80)$ minutes (Figure 1). The specificity studies showed that there were no interfering peaks near the retention time of ETU from blank sample matrix in all sample types, thus the method is specific for ETU (Figure 1). The calibration curves were linear from 1 to $200 \mathrm{ug} / \mathrm{L}$ for blood and environmental samples and for urine, it was linear from 1 to $2000 \mathrm{ug} / \mathrm{L}$, with regression coefficient of 0.99 and 0.95 , respectively. Figure 2 shows a sample calibration curve for blood with slope and intercept $(y=1.010 x+1.282)$. The observed limit of detection was $0.2 \mathrm{ug} / \mathrm{L}$ and the limit of quantitation was $0.5 \mathrm{ug} / \mathrm{L}$ for all sample types. The withinrun precision ranged from 3.33 to $12.86 \% \mathrm{CV}$ using the matrix-specific quality controls with concentrations of 1 , 10 and $100 \mathrm{ug} / \mathrm{L}$ of ETU. The accuracy was also $>90 \%$ at 1, 10 and $100 \mathrm{ug} / \mathrm{L}$ of ETU in all sample types. Table 1 shows the precision, accuracy and \% recovery of the HPLC determination of ETU in matrix-specific quality control samples. The observed limit of detection and linearity of this method is comparable with the analytical performance of methodologies used in published studies using more advanced techniques. ${ }^{11-15}$ Due to some safety concerns, an internal standard to ensure that any loss of the analyte in the step by step process is accounted for in every samples was the limitation of this method. However, an external standard of ETU with 3-5 concentrations were run in every analytical batch and subsequently, ETU concentration in the samples were based on the batch calibration curve.

After various sample preparation methods were tried and tested, pre-treatment and simple extraction procedure for all sample types was developed and validated. The reconstitution of the final extracts with the mobile phase, allows the same chromatographic condition in analyzing the various sample types, therefore, minimizing the changing of columns, mobile phase and even the instrument set up for each sample type. This approach made this method useful in environmental and health assessment studies for ETU, where various biological and environmental samples are submitted for analysis. Likewise, this validated method was found to be less complex as compared with the ETU methods reported in the literatures, requiring considerable number of reagents, complex procedures and careful handling to prevent the loss of ETU during the initial step in GC methods. ${ }^{7-10}$ Although gas chromatography is still the major technique in the analysis of ETU, the derivatization procedures to achieve sensitivity and

Table 1. Precision, \% accuracy and \% recovery of HPLC determination of ETU concentrations in matrix-specific quality control samples

\begin{tabular}{|c|c|c|c|}
\hline QC Sample (ug/L) & Mean $\pm S D(n=20)$ & Precision (\%CV) & Accuracy by \% Recovery \\
\hline \multicolumn{4}{|l|}{ ETU in Blood } \\
\hline 1.0 & $0.99 \pm 0.13$ & 12.86 & 99.4 \\
\hline 10.0 & $9.88 \pm 0.40$ & 4.05 & 98.8 \\
\hline 100.0 & $101.8+6.06$ & 5.95 & 101.8 \\
\hline \multicolumn{4}{|l|}{ ETU in Urine } \\
\hline 1.0 & $0.97 \pm 0.09$ & 9.28 & 96.6 \\
\hline 10.0 & $9.38 \pm 0.70$ & 7.46 & 93.8 \\
\hline 100.0 & $98.6+3.29$ & 3.34 & 98.6 \\
\hline \multicolumn{4}{|l|}{ ETU in Water } \\
\hline 1.0 & $0.90 \pm 0.03$ & 3.33 & 90.4 \\
\hline 10.0 & $9.10 \pm 0.71$ & 7.80 & 90.0 \\
\hline 100.0 & $101.0+3.54$ & 3.50 & 101.0 \\
\hline
\end{tabular}



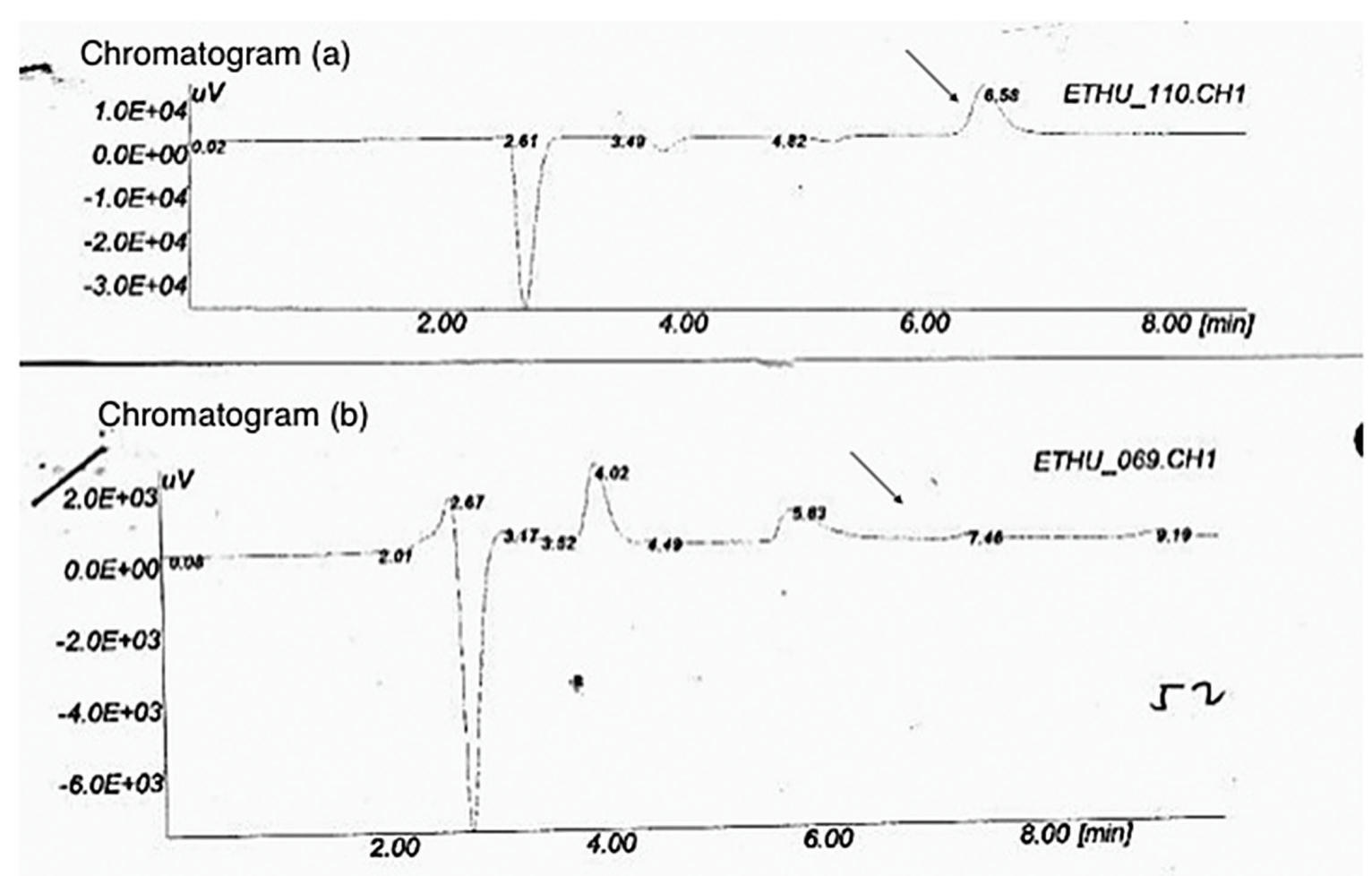

Figure 1. Chromatogram of urine spiked at $200 \mathrm{ug} / \mathrm{L}$ ETU and blank sample. Chromatogram (a) shows the retention time of ETU (200 ug/L) in urine at 6.58 minutes. Chromatogram (b) shows that the blank sample (ETU-free urine) did not show any peak at expected retention time of ETU.

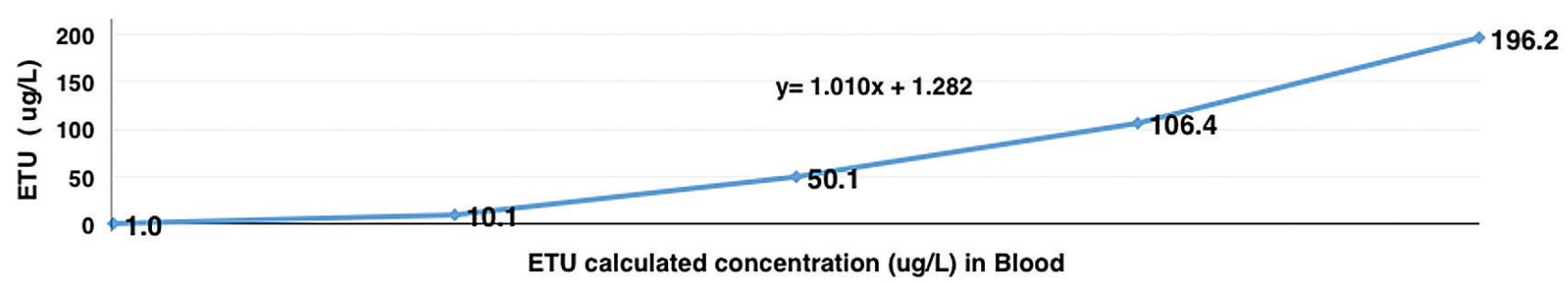

Figure 2. Calibration curve for ETU (ug/L) in blood. Correlation coefficient of standard curve by least-squares linear regression analysis was 0.99 .

specificity are, however, time consuming and ETU may be formed during reactions at elevated temperatures as a result of decomposition of EBDC residue present in the sample. Moreover, the recent methods reported in the literatures added some purification steps and utilized mass spectrometry, which are not easily adapted to laboratories with limited resources on advance technologies. ${ }^{11-17}$

After this method passed all the validation acceptance criteria and showed an acceptable accuracy, precision, sensitivity and specificity for the determination of ETU, biological samples (blood and urine) and environmental samples (water, soil and air filter) collected for the health assessment study among banana plantation workers in the Philippines were analyzed for ETU using this validated method. ${ }^{19}$ Analytical methods for ETU using technology available in most of the laboratories, such as HPLC with simple pre-treatment and extraction procedures as described in this study, will most likely make routine assessment in the fields more feasible. More human studies on EBDC and its metabolite ETU, will lead to better understanding of the relation of its health effects and levels of exposures. ${ }^{20}$

\section{CONCLUSION}

This HPLC method showed an acceptable accuracy, precision, sensitivity and specificity for the determination of ETU in blood, urine, water, soil and air. Its limit of detection and linearity are comparable with advance methodologies, ${ }^{11-15}$ thus provides an alternative to laboratories, with limited resources on instrumentation such as mass spectrometry, the capacity to determine ETU in biological and environmental samples as indicator of EBDC exposure. 


\section{Acknowledgments}

The authors extend gratitude for this collaborative work to the Department of Pharmacology and Toxicology, College of Medicine, University of The Philippines-Manila for providing the laboratory facility for all the analytical work and to the National Poison Management and Control Center, University of the Philippines - Philippine General Hospital for the logistics during sample collection and the technical support during the entire duration of the research project.

\section{Statement of Authorship}

All authors have approved the final version submitted.

\section{Author Disclosure}

All the authors declared no conflict of interest.

\section{Funding Source}

This paper was funded by the National Poison Management and Control Center, University of the Philippines - Philippine General Hospital and the NonCommunicable Disease Unit, Department of Health, Philippines.

\section{REFERENCES}

1. Houeto P, Bindoula G, Hoffman JR. Ehylenebisdithiocarbamantes and ethylenethiourea: possible human health hazards. Environ Health Perspect. 1995; 103(6):568-73.

2. WHO. Environmental Heath Criteria 78. Dithiocarbamate Pesticides, Ethylene thiourea and Propylenethiourea: A General Introduction. International Programme on Chemical Safety [Online]. 1988 [cited 2017 Jul]. Available from http://www.inchem.org.documents/ehc/ ehc/ehc78.html

3. IARC Monographs. Ethylene Thiourea - Summaries and Evaluations [Online]. 2001 [cited 2017 Jul]. Available from http://www.inchem. orh/documents/iarc/vol79/79-18.html

4. Lentza-Rizos C. Ethylene thiourea (ETU) in relation to use of Ethylenebisdithiocarbamate (EBDC) fungicides. Rev Environ Contam Toxicol. 1990; 115:1-37.

5. van Wendel de Joode B, Mora AM, Cordoba L, et.al. Aerial application of mancozeb and urinary ethylene thiourea (ETU) concentrations among pregnant women in Costa Rica: the infants' environmental health study (ISA). Environ Health Perspect. 2014; 122(12):1321-8.

6. Gullino ML, Tinivella F, Garibaldi A, Kemmit GM, Bacci L, Sheppard B. Mancozeb: past, present, future. Plant Dis. 2010; 94:1076-87.
7. Hirvi T, Pysalo H, Savolainen K. A glass capillary liquid chromatography method for determining Ethylenethiourea without derivatization. J Agric Food Chem.1979; 27(1):194-5.

8. El Balkhi S, Sandouk P, Galliot-Guilley M. Determination of ethylene thiourea in urine by HPLC-DAD. J Anal Toxicol. 2005; 29(4):229-33.

9. Debbarh I, Moore N. A simple method for the determination of ethylene-thiourea (ETU) in biological samples. J Anal Toxicol. 2002; 26(4):216-21.

10. Kurtio P, Vartianen T, Savolainen K. Environmental and biological monitoring of exposure to Ethylenebisdithiocarbamate fungicides and Ethylenethiourea. Br J Ind Med. 1990; 47(3):203-6.

11. Colosio C, Vicentin S, Birindelli S, et al. Reference values for ethylene thiourea in urine in Northern Italy: results of a pilot study. Toxicol Lett. 2006; 162(2-3):153-7.

12. Colosio C, Fustinoni S, Birindelli S, et.al. Ethylene thiourea in urine as an indicator of exposure to mancozeb in vineyard workers. Toxicol Lett. 2002; 134(1-3):133-40.

13. Fustinoni S, Campo L, Colosio C, Birendelli S, Foa V. Application of gas chromatography-mass spectrometry for the determination of urinary ethylene thiourea in humans. J Chromatogr B Analyt Technol Biomed Life Sci. 2005; 814(2):251-8.

14. Ekman E, Maxe M, Littorin M, Jonsson BA, Lindh CH. Highthroughput method for the analysis of Ethylenethiourea with direct injection of hydrolyzed urine using online on-column extraction liquid chromatography and triple quadropole mass spectrometry. J Chromatogr B Analyt Technol Biomed Life Sci. 2013; 934:53-9.

15. Ripolles C, SanchoJV,Lopez FJ, Hernandez F. Liquid chromatography coupled to tandem mass spectrometry for the residue determination of Ethylenethiourea (ETU) and propylenethiourea (PTU) in water. J Chromatogr A. 2012; 1243:53-61.

16. Jones K, Patel K, Cocker J, Bevan R, Levy L. Determination of ethylene thiourea in urine by liquid chromatography-atmospheric pressure chemical ionisation-mass spectrometry for monitoring background levels in the general population. J Chromatogr B Analyt Technol Biomed Life Sci. 2010; 878(27):2563-6.

17. Lindh $\mathrm{CH}$, Littorin $\mathrm{M}$, Johannesson $\mathrm{G}$, Jonsson BA. Analysis of ethylene thiourea as a biomarker in human urine using liquid chromatography/triple quadruple mass spectrometry. Rapid Commun Mass Spectrom. 2008;22(16):2573-9.

18. Kobayashi H, Kaneda M, Teramoto S. Identification of 1-methylthiourea as the metabolite of Ethylenethiourea in rats by high performance liquid chromatography. Toxicol Lett. 1982; 12(2-3):109-13.

19. Panganiban L, Cortes-Maramba N, Dioquino C, et al. Correlation between blood Ethylenethiourea and thyroid gland disorders among banana plantation workers in the Philippines. EnvironHealth Perspect. 2004; 112(1):42-5.

20. Montesano A, Wang R. Biomonitoring of Contemporary Pesticides: Ethylenethiourea in Occupational Settings, Pesticides in the Modern World-Effects of Pesticides Exposure [Online]. 2011 [cited 2017 Jul]. Available from http://.cdn.intechweb.org/pdfs/19598.pdf 